\title{
Does height influence progression through primary school grades?
}

\author{
Melissa Wake, David Coghlan, Kylie Hesketh
}

\begin{abstract}
Aim-To examine the relation between a child's height and grade progression in primary school.

Methods-Height was measured in a representative cross sectional sample of children from 24 primary schools in Victoria in late 1997. Height measurements were transformed to standardised scores using Cole's "LMS" method to allow for comparison across ages and genders. Children within each grade were divided into three equal groups based on age (youngest third, middle third, oldest third), again to allow for cross age comparison.

Results-A total of 2848 children aged 5-12 years (51\% male) were included, with approximately 400 children in each of the seven grades from preparatory to grade 6 . Analysis of variance showed a significant relation overall between age and height, with a sequential decrease in height from the youngest to the oldest third. When genders were considered separately, the relation remained significant for boys but not for girls. A total of 133 children (66\% male) repeated a grade in primary school. When this group of grade repeaters was removed from the sample, analysis of variance showed no significant relation between standardised height score and age tertile for boys. Although birth weight category and maternal education were independent predictors of height scores overall, they did not appear to influence decisions to retain pupils in grades.

Conclusions-Older boys within grades, notably those who have repeated a grade, are shorter than their peers. Decisions to retain pupils, particularly boys who are experiencing school difficulties, may be influenced by their height. (Arch Dis Child 2000;82:297-301)
\end{abstract}

Research and Policy Unit, Centre for Community Child Health, Royal Children's Hospital, Flemington Road, Parkville, VIC 3052, Australia

M Wake

D Coghlan

K Hesketh

Correspondence to: Dr Wake

email: wakem@

cryptic.rch.unimelb.edu.au

Accepted 22 November 1999
Keywords: school age; height; grade retention; birthweight

Parents and early childhood workers spend much time pondering school readiness issues for preschoolers and the possibility of grade retention for older children experiencing school difficulties. Factors such as "immaturity", younger age, and cognitive abilities may be taken into account in making such decisions. Anecdotally, another factor-a child's stature - is often also considered: will the child stand out too much? The influence a child's stature may have on school commencement and grade advancement has not previously been addressed in the literature.

A child's height could contribute to decisions about school commencement and then progression through the early school grades in two ways. Firstly, there is some evidence that a child's height influences the way in which that child is perceived. Among adults there is a tendency to treat children at a size appropriate rather than age appropriate level. ${ }^{1}$ Age tends to be underestimated in shorter children and this can leave them "infantilised" within the peer group. ${ }^{1}$ Conversely, taller children have consistently been reported as more mature than their age matched classmates. ${ }^{2}{ }^{3}$ There is also evidence that adult expectations of and reinforcements given to school age children vary according to a child's height. ${ }^{4}$ Secondly, there are relations between a child's stature and their school performance and intelligence that go beyond simple perceptions based on stature. ${ }^{45}$ Very small children (below the 3rd centile for height) may have lower, though usually normal, mean IQ scores than children of normal height. ${ }^{4-6}$ In the recent Wessex Growth Study, more short normal children were from the lower social classes, ${ }^{7}$ which could reflect current nutritional and health disadvantage as well as systematic economic discrimination over generations against adults with familial short stature. Large US studies of normal school populations revealed taller children to be more capable on a range of cognitive and academic achievement tests. ${ }^{8}$ Data from the 1970 National Health Examination Survey showed that early maturing boys, who were taller at the time of study, had much higher parental aspirations and expectations concerning their level of education. ${ }^{3}$ Tall stature is not necessarily seen as advantageous for girls however, and many more girls than boys seek psychological help for issues regarding tall stature. ${ }^{9}$

No published reports have examined the relation between advancement through the early school grades and height. We tested the hypothesis that shorter children are more likely to repeat a grade in the early school years and that taller children are more likely to advance during this period. We aimed to assess this in the absence of any previous reports, while controlling for possible confounders such as birth weight, maternal education, and socioeconomic grouping.

\section{Methods}

SAMPLE

This study was conducted within a larger epidemiological study, the Health of Young Victorians Study (HOYVS), which investigated 
the health and wellbeing of schoolchildren in Victoria. The sample consisted of all primary schoolchildren taking part in the HOYVS for whom height data were available. The sample of 24 schools was drawn using a two stage stratified random sampling design. In the first stage schools were stratified by school sector (government, Catholic, and independent) and selected with a probability proportional to size. In the second stage, one intact class at each year level (preparatory to grade 6) was randomly selected at each school to participate in the study, unless the total school population was less than 240 students in which case the entire school was sampled. In Victoria, children enter primary school (preparatory grade) at approximately 5 years of age. Informed consent was obtained from a parent or guardian for each participant.

MEASUREMENTS

For each child, height was measured using the freestanding Invicta portable stadiometer, which reads to the nearest $1 \mathrm{~mm}$ up to $207 \mathrm{~cm}$ and needs no calibration. ${ }^{10}$ Children were measured without shoes by trained researchers using standard protocols based on the 1985 Australian Health and Fitness Survey. ${ }^{11}$ All measurements took place between September and December 1997.

Sociodemographic information was collected from parents of participating children by way of a questionnaire completed at home.

\section{ANALYSES}

Height measurements were transformed to standardised scores using Cole's "LMS" method to allow for comparison across ages and genders. This method uses the 1990 British growth reference data to provide a standard deviation score ( $\mathrm{z}$ score) based on the child's exact age and gender. ${ }^{12}$

Children within each school grade were divided into equal thirds (tertiles) based on age (youngest third, middle third, oldest third) to allow us to study relations between relative age and standardised height across classes.

The main analyses used were $\chi^{2}$ statistics or Fisher's exact test as appropriate for categorical analyses and analysis of variance or covariance as appropriate for describing group mean differences.

Ethics approval for the study was obtained from the Royal Children's Hospital Ethics in Human Research Committee.

\section{Results}

SUBJECTS

A total of 3104 children participated in the primary school subsample of the Health of Young Victorians Study (75\% response). Of these, 2848 children aged $5-12$ years ( $51 \%$ male) had complete height and parent questionnaire data and were therefore included in these analyses. There were an average of 407 children from each grade level (range 356-435 per grade level). Table 1 presents sample characteristics for boys and girls.

STANDARD DEVIATION SCORES

The mean standard deviation height score for the sample was 0.25 , indicating that children in this sample were slightly taller than those in the 1990 British growth reference sample. The transformation resulted in a normally distributed sample of standard deviation height scores (SD 1.01).

STANDARD DEVIATION HEIGHT SCORES AND SCHOOL GRADE

Analysis of variance showed a small but significant relation overall between age tertile and standard deviation height scores, with a sequential decrease in standard deviation height scores from children in the youngest thirds of their grades to those in the oldest thirds $\left(F=3.1_{2,2845}, \mathrm{p}<0.05\right)$. As would be expected from the transformation used, there was no relation between standard deviation height scores and gender. However, when genders were analysed separately, the significant overall relation between age tertile and standard deviation height score was found only in boys $\left(F=4.6_{2,1436}, \mathrm{p}<0.01\right)$ with no significant relation found for girls $\left(F=0.85_{2,1406}\right.$, $\mathrm{p}=0.43)$. In other words, within grades older boys were found to be overall relatively shorter than younger boys (table 2 ).

Table 1 Sample characteristics

\begin{tabular}{|c|c|c|}
\hline Characteristic & Boys & Girls \\
\hline Number of subjects & 1439 & 1409 \\
\hline Age $(\mathrm{y})$-mean (SD) (range) & $9.14(2.02)(5.37-13.61)$ & $9.03(2.01)(5.03-13.57)$ \\
\hline Standard deviation height score-mean (SD) & $0.27(0.99)$ & $0.22(1.04)$ \\
\hline Birth weight $(\mathrm{kg})$ - mean (SD) & $3.44(0.56)$ & $3.32(0.57)$ \\
\hline Number of children who had repeated a grade & 88 & 45 \\
\hline \multicolumn{3}{|l|}{ Maternal education $(\%)^{\star}$} \\
\hline$\leqslant$ Year 10 & 27 & 28 \\
\hline Year 11/12 & 31 & 31 \\
\hline Trade apprenticeship/technical diploma & 16 & 15 \\
\hline Tertiary/postgraduate degree & 21 & 20 \\
\hline \multicolumn{3}{|l|}{ Paternal education $(\%)^{\star}$} \\
\hline$\leqslant$ Year 10 & 20 & 19 \\
\hline Year 11/12 & 17 & 18 \\
\hline Trade apprenticeship/technical diploma & 30 & 32 \\
\hline Tertiary/postgraduate degree & 22 & 20 \\
\hline \multicolumn{3}{|l|}{ Responding parent's country of birth $(\%)^{\star}$} \\
\hline Australia/New Zealand & 72 & 72 \\
\hline Other English speaking & 7 & 7 \\
\hline South East Asian & 2 & 2 \\
\hline Eastern European & 2 & 2 \\
\hline Mediterranean & 3 & 4 \\
\hline
\end{tabular}

$\star$ Percentages do not add up to 100 due to missing data. 
Table 2 Standard deviation height scores by age tertile within grades

\begin{tabular}{|c|c|c|c|c|c|c|c|c|c|c|c|c|}
\hline \multirow[b]{3}{*}{ Grade } & \multicolumn{6}{|l|}{ Boys } & \multicolumn{6}{|l|}{ Girls } \\
\hline & \multirow[b]{2}{*}{$n$} & \multicolumn{3}{|c|}{$\begin{array}{l}\text { Standard deviation height score } \\
\text { (mean) }\end{array}$} & \multirow[b]{2}{*}{$F$} & \multirow[b]{2}{*}{$p$} & \multirow[b]{2}{*}{$n$} & \multicolumn{3}{|c|}{$\begin{array}{l}\text { Standard deviation height score } \\
\text { (mean) }\end{array}$} & \multirow[b]{2}{*}{$F$} & \multirow[b]{2}{*}{$p$} \\
\hline & & $\begin{array}{l}\text { Youngest } \\
\text { tertile }\end{array}$ & $\begin{array}{l}\text { Middle } \\
\text { tertile }\end{array}$ & $\begin{array}{l}\text { Oldest } \\
\text { tertile }\end{array}$ & & & & $\begin{array}{l}\text { Youngest } \\
\text { tertile }\end{array}$ & $\begin{array}{l}\text { Middle } \\
\text { tertile }\end{array}$ & $\begin{array}{l}\text { Oldest } \\
\text { tertile }\end{array}$ & & \\
\hline $\begin{array}{l}\text { All grades } \\
\text { Current grade }\end{array}$ & 1439 & 0.33 & 0.33 & 0.16 & 4.57 & 0.01 & 1409 & 0.27 & 0.18 & 0.21 & 0.85 & 0.43 \\
\hline Preparatory & 209 & 0.21 & 0.16 & 0.30 & 0.36 & 0.70 & 212 & 0.34 & 0.07 & 0.20 & 1.15 & 0.32 \\
\hline 1 & 178 & 0.37 & 0.35 & 0.04 & 1.95 & 0.15 & 178 & 0.28 & 0.42 & 0.25 & 0.39 & 0.68 \\
\hline 2 & 218 & 0.45 & 0.30 & 0.09 & 2.61 & 0.08 & 207 & 0.45 & 0.26 & 0.13 & 1.66 & 0.19 \\
\hline 3 & 216 & 0.29 & 0.31 & 0.24 & 0.08 & 0.92 & 216 & 0.22 & 0.01 & 0.24 & 1.27 & 0.28 \\
\hline 4 & 223 & 0.25 & 0.41 & 0.04 & 2.83 & 0.06 & 212 & 0.17 & 0.13 & 0.20 & 0.07 & 0.94 \\
\hline 5 & 181 & 0.59 & 0.28 & 0.11 & 3.31 & 0.04 & 193 & -0.01 & 0.23 & 0.14 & 0.99 & 0.38 \\
\hline 6 & 214 & 0.20 & 0.46 & 0.29 & 1.38 & 0.25 & 191 & 0.43 & 0.19 & 0.31 & 0.88 & 0.42 \\
\hline
\end{tabular}

When the male sample was analysed by individual grade levels and gender, the relation between age tertile and standard deviation height scores remained significant for grade 5 boys only $\left(F=3.3_{2,178}, \mathrm{p}<0.05\right)$ although the relation for grade 2 and grade 4 boys approached significance. These analyses were based on small cells of only 178-223 boys.

As previous research has concentrated on children at the extremes of height, we also considered children whose heights fell at less than the 3rd centile and those whose heights exceeded the 97th centile. Pearson's $\chi^{2}$ test indicated that children with heights less than the $3 \mathrm{rd}$ centile were not more likely to be in the oldest for class tertile than children with heights greater than the 3 rd centile $\left(\chi^{2}=2.0\right.$, $\mathrm{p}=0.15)$. Similarly, those with heights greater than the 97 th centile were not more likely to be in the youngest for class tertile than other children $\left(\chi^{2}=0.72, p=0.40\right)$. In other words, there appeared to be no relation between extreme height and age tertile. However, these analyses were based on relatively small cells with only 84 and 85 children respectively falling in the lower and upper centiles of height.

Owing to the significant gender difference found in the relation between age tertile and standard deviation height score, all subsequent analyses were conducted separately for boys and girls.

SOCIODEMOGRAPHIC INFLUENCES

Maternal and paternal education (Year 10 or below, Year 11/12, trade apprenticeship/ technical diploma, tertiary/postgraduate degree) independently predicted standard deviation height score for girls $\left(F=4.9_{3,1327}\right.$, $\mathrm{p}<0.01 ; F=2.8_{3,1245}, \mathrm{p}<0.05$ respectively) but not for boys $\left(F=0.7_{3,1365}, \quad \mathrm{p}=0.55\right.$; $F=1.7_{3,1274}, \mathrm{p}=0.17$ respectively), with taller girls generally having more highly educated mothers and fathers. This relation did not change the overall relation between standard deviation height score and age tertile for either gender. Neither maternal nor paternal employment status significantly predicted a child's standard deviation height score for boys or girls.

CHILDREN WHO HAD REPEATED A GRADE A total of 88 boys and 45 girls were reported to have repeated a grade at primary school (table $3)$. When these children were removed from
Table 3 Standard deviation height scores of children who have and have not repeated a grade

\begin{tabular}{|c|c|c|c|c|}
\hline & \multicolumn{2}{|c|}{ Standard deviation height score } & \multirow[b]{2}{*}{$t$} & \multirow[b]{2}{*}{$p$} \\
\hline & $\begin{array}{l}\text { Never repeated } \\
\text { mean } S D(n)\end{array}$ & $\begin{array}{l}\text { Ever repeated } \\
\text { mean } S D(n)\end{array}$ & & \\
\hline All children & $\begin{array}{l}0.26 \\
1.01(2715)\end{array}$ & $\begin{array}{l}0.06 \\
1.11(129)\end{array}$ & -2.18 & 0.03 \\
\hline Boys & $\begin{array}{l}0.30 \\
0.97(1349)\end{array}$ & $\begin{array}{l}-0.04 \\
1.17(86)\end{array}$ & -3.09 & 0.01 \\
\hline Girls & $\begin{array}{l}0.22 \\
1.04(1366)\end{array}$ & $\begin{array}{l}0.26 \\
0.94(43)\end{array}$ & 0.25 & 0.81 \\
\hline
\end{tabular}

the sample, there was no longer a significant relation between standard deviation height score and age tertile for boys $\left(F=1.35_{2,1340}\right.$, $\mathrm{p}=0.26)$. For girls, the relation remained non-significant when children who had repeated a grade were removed from the sample $\left(F=0.99_{2,1353}, \mathrm{p}=0.37\right)$.

As would be expected, most of the children who had repeated a grade fell into the oldest third for current grade group ( $88 \%$ of boys and $84 \%$ of girls). For boys, the mean standard deviation height score of these children was significantly lower than that of children in the oldest third for grade group who had never repeated a grade $(-0.14$ versus 0.23 , $\mathrm{p}<0.004)$. For girls, there was no difference (0.20 versus $0.21, \mathrm{p}=0.97$ ).

BIRTH WEIGHT

To examine whether birth weight contributed to the relation between grade retention and standard deviation height scores owing to its known associations with growth and with cognition, birth weight was divided into standard categories: very low (1-1.5 kg), low (1.6-2.5 $\mathrm{kg}$ ), average $(2.6-3.5 \mathrm{~kg})$, and greater than average $(>3.5 \mathrm{~kg})$. No subjects were reported to have had extremely low birth weight $(<1 \mathrm{~kg})$.

Overall, birth weight independently predicted standard deviation height score for girls $\left(F=24.8_{3,1371}, \quad \mathrm{p}<0.001\right)$ and for boys $\left(F=16.5_{3,1400}, \quad \mathrm{p}<0.001\right)$. However, when birth weight was dichotomised into low (incorporating the very low and low categories) and not low (incorporating the average and greater than average categories) there was no relation between birth weight and grade retention overall $\left(\chi^{2}=0.89, p=0.35\right)$, nor for boys or girls individually $(\mathrm{p}=0.19, \mathrm{p}=0.74$ respectively; two tailed Fisher's exact test; table 4). 
Table 4 Birth weight category versus current standard deviation height score for children who have and have not repeated a grade at primary school

\begin{tabular}{lllll}
\hline \multicolumn{5}{l}{ Standard deviation height score } \\
& $\begin{array}{l}\text { Low birth weight } \\
1.0-1.5 \mathrm{~kg}\end{array}$ & $1.5-2.5 \mathrm{~kg}$ & $\begin{array}{l}\text { Average birth weight } \\
2.5-3.5 \mathrm{~kg}\end{array}$ & $>3.5 \mathrm{~kg}$ \\
\hline Boys & & & & \\
Never repeated & 0.02 & -0.11 & 0.15 & 0.49 \\
Ever repeated & $0.30(4)$ & $1.06(56)$ & $0.95(636)$ & $0.95(620)$ \\
Girls & -0.09 & 0.22 & -0.12 & 0.06 \\
Never repeated & $0.62(2)$ & $2.27(5)$ & $1.11(44)$ & $1.11(34)$ \\
Ever repeated & -0.69 & -0.29 & 0.11 & 0.52 \\
& $1.41(9)$ & $1.09(77)$ & $1.00(777)$ & $1.01(473)$ \\
& 0.66 & -0.74 & 0.30 & 0.28 \\
& $0.38(2)$ & $\mathrm{n} / \mathrm{a}(1)$ & $0.90(25)$ & $1.12(12)$ \\
\hline
\end{tabular}

ETHNIC BACKGROUND

Place of birth of the responding parent was taken to represent ethnic background. Seventy two per cent of responding parents were born in Australia or New Zealand and 7\% were born in another English speaking country (for example, UK, USA). The remaining countries of birth were categorised into South East Asian $(2 \%)$, Eastern European (2\%), and Mediterranean $(3 \%)$.

Overall, parent place of birth independently predicted standard deviation height scores for girls $\left(F=4.2_{4,1297}, \mathrm{p}<0.01\right)$ and for boys $\left(F=4.6_{4,1313}, \mathrm{p}<0.001\right)$. Bonferroni post hoc tests showed that boys and girls of South East Asian background were significantly shorter than children whose responding parent was born in Australia/New Zealand or another English speaking country. However, as only one of the 70 children of South East Asian background had repeated a grade, this could not have accounted for the observed relation between height and grade retention.

\section{Discussion}

Our data showed that older boys within grades were relatively shorter than their younger peers. The group of boys who had repeated a grade, who were relatively short for their age, appeared to be responsible for this relation. In other words, when boys experience school difficulties, height may indeed be one factor influencing the final decision to retain.

This relation could not be explained by sociodemographic factors, ethnic background, or by maternal/paternal education levels (our proxy for child IQ). It did not appear to be mediated by birthweight. As expected, children of low birthweight were more likely to remain relatively small for age, but this did not appear to influence decisions to retain.

There is little doubt that height, cognitive ability, and achievement are interrelated for both boys and girls. For example, Weinberg's study of 334 children aged 8 and 9 years found that taller children tend to have higher IQ scores. ${ }^{6}$ Data from the National Health Examination Survey (cycles 2 and 3) in a sample of 13887 US children aged 6 to 17 years showed WISC and WRAT scores to be significantly associated with height $\mathrm{z}$ score. ${ }^{8}$ This relation is most notable for extremely short children (less than 3 rd centile), as shown by the UK Wessex study in which short children had lower IQ attainment (102.6 versus 108.6, p < 0.005) than controls of normal stature. However, as we found no relation between height and grade retention for girls in our study, we do not believe that the height/achievement correlation alone would be likely to explain our findings. While the smaller boys may have been performing overall less well than the taller boys, it seems more likely that the short stature "tipped the balance" for parents and teachers when making decisions about retention for boys (and not girls) experiencing school difficulty.

We found little evidence that taller children originated from more socially advantaged backgrounds, other than a small relation between parental education and girls' standard deviation height scores. In the past, social class has been a major determinant of height, mainly for nutritional and physical health reasons, and it is pleasing that this no longer seems to be the case for children in Victoria in the 1990s. ${ }^{13}$ Of course, social disadvantage continues to influence children's academic and cognitive outcomes enormously. ${ }^{14}$

There were several limitations to this study. Firstly, we did not formally assess cognitive abilities or academic achievement for these children. As this was a cross sectional study, we have no follow up data on subsequent height measurements of these children; ideally, one would like to follow a cohort of children over time and observe the effects of height on grade advancement. Our overall response rate of $75 \%$ was satisfactory. Country of birth of responding parents did not influence the study results, but our findings may not generalise to children of ethnic background whose parents were not literate in English to at least the Grade 6-7 level required by the questionnaire. This should not however reduce the internal validity of the findings reported here. It is possible, though does not seem very likely, that some parents, knowing their child to be small, may have refused to give consent. The division of the grades into age tertiles, for the purpose of comparison, was arbitrary but in the absence of other models seemed appropriate.

In summary, we found no evidence that height influences choices as to when a child starts school or that it influences the progress of girls at any stage. This is encouraging, given that repeating a grade is of questionable benefit, and may even be detrimental to a child's later functioning. ${ }^{1516}$ However, there was some evidence that height may influence the early school progress of boys. This may be one example of a societal perception of childhood ability that is biased against smaller children. An awareness that children of smaller stature may be disadvantaged by such societal perceptions may help in correcting these inequalities.

We would like to acknowledge the financial grant provided by the Victorian Department of Human Services Division of Public Health, which made this project possible. We would also like to thank Louisa Salmon, John Birchall, and Lisa Templeton who assisted with the field measurements.

1 Law CM. The disability of short stature. Arch Dis Child 1987;62:855-9. 
2 Underwood LE. The societal cost of being short: societal perceptions and biases. Acta Paediatr Scand 1991;377:3-8.
Duke PM, Jennings D, Dornbusch SM, Gross R. EduDuke PM, Jennings D, Dornbusch SM, Gross R. Educational correlates of early and late sexu

4 Skuse D, Gilmour J, Tian CS, Hindmarsh P. Psychosocial assessment of children with short stature: a preliminary report. Acta Paediatr 1994;406:11-16.

5 Downie AB, Mulligan J, Stratford RJ, Betts PR, Voss LD. Are short normal children at a disadvantage? The Wessex growth study. BMF 1997;314:97-100

6 Weinberg WA, Dietz SG, Penick EC, McAlister WH. Intelligence, reading achievement, physical size, and social class. F Pediatr 1974;:85:482-9.

7 Voss LD, Mulligan J, Betts PR. Short stature at school entry - an index of social deprivation? (The Wessex Growth Study). Child Care Health Dev 1998;24:145-56.

8 Wilson DM, Hammer LD, Duncan PM, Dornbusch SM, Gross RT. Growth and intellectual development. Pediatrics 1986;78:646-50.

9 Binder G, Grauer ML, Wehner AV, Wehner F, Ranke MB. Outcome in tall stature. Final height and psychological aspects in 220 patients with and without treatment. Eur $\mathcal{F}$ Pediatr 1997;156:905-10.
10 Voss LD, Bailey BJ. Equipping the community to measure children's height: the reliability of portable instruments. Arch Dis Child 1994;70:469-71

11 Australian Council for Health Physical Education and Recreation. Australian health and fitness survey 1985. Adelaide: ACHPER Publications, 1985.

12 Cole TJ, Green PJ. Smoothing reference centile curves: the LMS method and penalized likelihood. Stat Med 1992;11: 1305-19.

13 Spencer N. Race and ethnicity as determinants of child health: a personal view. Child Care Health Dev 1996;22: 327-45.

14 Bacharach VR, Baumeister AA. Effects of maternal intelligence, marital status, income, and home environment on cognitive development of low birthweight infants. $f$ Pediatr Psychol 1998;23:197-205.

15 Byrd RS, Weitzman ML. Predictors of early grade retention among children in the United States. Pediatrics 1994;93: 481-7.

16 Byrd RS, Weitzman ML, Auinger P. Increased behaviour problems associated with delayed school entry and delayed school progress. Pediatrics 1997;100:654-61. 